\title{
New Technologies among Evenki Hunter-Gatherers in East Siberia
}

\author{
A Photographic Analysis
}

\author{
Tatiana Safonova - István Sántha \\ Central European University, Budapest - Institute of Ethnology, \\ $\mathrm{RCH}$, Hungarian Academy of Sciences, Budapest
}

\begin{abstract}
This article presents some results of the photographic analysis project, that we accomplish on the basis of 17,000 photos shot during the anthropological fieldwork between October 2008 and November 2009 among Evenki living in East Buryatia, in the Eastern part of Siberia. The aim of the project is to study the non-verbal patterns of culture. Some activities are significant due to the natural environment and the peripheral position of the Evenki land. Modern and old instruments can be seen together in the taiga, they relate to each other and form pairs. The existence of these pairs show the necessity of the co-presence of modern and old technologies and the importance of the categories - activities - tasks connected with them. An old instrument can remain among the Evenki only if an adaptable new instrument can find its place in the everyday life. Sometimes old practical skills also need to be reinvented for the accomplishment of a particular task. The things which have no modern existing pair, step by step lose their place and extinguish.
\end{abstract}

Keywords: technology, photographies, hunter-gatherers, social anthropology, modernity, Russia

This paper is an image-article about the atmosphere of life in the taiga. It is an anthropological account created in the tradition initiated by Gregory Bateson and Margaret Mead with their seminal work Balinese Character (Bateson - Mead 1942), which was an important source of inspiration for other famous co-authors; namely Gilles Deleuze and Félix Guattari during writing of their influential $A$ Thousand Plateaus (Deleauze-Guattari 1987). With these two books in mind, we delved into the world of the modern Siberian taiga, where Evenki hunters live. In the course of fieldwork conducted in 2008-2009, we amassed more than 17,000 photos, all of them visual documents reflecting the atmosphere of Evenki life. Although most anthropologists have ignored the genre of Balinese Character, we argue that the form of photographic analysis it offered deserves to become an independent methodological approach. In this article, and through photographic analysis, we serendipitously rediscover traditional anthropological themes, such as hunter-gatherers, while reflecting on the way these practices fit with the designs of new technological devices and global infrastructures. 
Multiplicity and anarchic uncertainty are the prevailing characteristics of the Evenki environment. Bipolar contrasts do not dominate the Evenki land. In modern Russia, enormous multiple opportunities in conjunction with the development of resourcebased capitalism generate unpredictability and uncertainty. Here, it is not possible to distinguish between tradition and modernity; a caustic climate is no longer an obstacle. On the contrary, it presents an opportunity for invasion and the colonization of resources. The future is capricious, not because of the complexity of external influences (global market fluctuations, for example), but due to seemingly inadequate local reactions to external complexities. Initially, the porous nature of the infrastructure becomes apparent: wherever one goes, gaps and distortions are visible - roads do not complement bridges, fences have holes, satellite telephones that connect villages operate only for a few hours a day, when a settlement has electricity. These gaps in the networks of infrastructure create the unique atmosphere of a given location, the main paradox being that gaps and absences become the building blocks for local infrastructure. They are visible, albeit containing voids, which is why the visual methodology of Balinese Character is the most suitable approach to studying the Evenki land.

In this paper, we propose to contemplate technologies as framed by an ecology of practice in which new and old technologies are in a symbiotic relationship. We also elucidate why the life of the Evenki appears to be both deeply conservative and progressive simultaneously. The theoretical rhizomes of the research spread out across the cybernetic approach initially developed by Gregory Bateson, a theory of effect (in its Deleuzian form), in approaches to infrastructure Michel Serres' concept of parasite and noise: (SERRES 2007), as well as anthropological research on infrastructure conducted by Julia Elyachar (ElYaChar 2010), Brian Larkin (LARKIN 2008), Bill Maurer (MAURER 2005) and Paul Kockelman (KocKelman 2013), the philosophy of science (Isabelle Stengers' ecology of practice; STENGERs 2013), new materialism (Jane Bennett's vibrant matter: BENNETT 2010) and autopoiesis (LUHMANN 1996).

The paper is of interest to specialists in visual anthropology, researchers of huntergathering peoples and scholars in Siberian studies as well as all who are interested in the cybernetic approach and its current transformations. This article may also prove useful in courses for students studying the history of visual anthropology and anthropological research methods.

In the course of our fieldwork among the Evenki, we have observed that Evenki people are not conservative with respect to preserving their traditions, at least not in terms of clinging to their old physical possessions at all costs. They show an enthusiastic interest in all new devices that can be utilised in their lives. They are keen to try them, and if their attempts prove useful, they seek them in the future as well. Regarding the issue of modernity, we believe that the basic contours of Evenki culture can be more effectively depicted through the analysis of problem-solving activities rather than by examining the use of everyday tools and objects, and not by describing an equalitybased social organisation or some kind of modern hunter-gatherer ethos. The result of modernity is that the Evenki are able to make use of certain tools and opportunities while not being able to do so with others. The taiga provides a very limited range of goods suitable for long-term consumption and that can actually be obtained. On the other hand, it should be mentioned that the logic of consumer culture is not valid here because the Evenki society is adjusted to poverty. 
When analysing our Evenki materials, it is necessary to consider various approaches to the concept of "modernity", firstly with regards to the term "modern hunter-gatherer", which began to appear in professional literature during the 1980s in connection with present day hunter-gatherers as opposed to pre-historic peoples. It should be noted here that it is impossible to find any group of hunter-gatherers today where the issue of modernity cannot or should not be examined. In keeping with this approach, every aspect in connection with Evenki life today can be discussed within the scope of modernity. Using another opportunity to approach the issue of modernisation, which we will attempt to apply later in this study, and rather than examining the interests of the state and the role of globalisation, we shall focus on how the Evenki utilise the tools and devices they encounter in their lives. Finally, the most frequent interpretation of the term focuses on efforts made by the state in connection with minorities, in this case the Evenki. On the basis of his anthropological field studies conducted in Zambia, James Ferguson concluded that modernisation is nothing more than a myth (in this regard no different from other myths) which facilitates understanding of and orientation within the world, making available basic categories and guidelines that enable people to discuss and interpret their life experiences (FERGUSON 1999:4). In this sense, Evenki people could indeed be considered an exception since neither myth-oriented thinking nor verbal expression hold any practical significance for them. Even so, using Russia in general as a basis, this approach can be effectively applied when presenting accounts that have already become stereotypical.

\section{THE EVENKI AND THE STATE}

The confines of the taiga, to which the Evenki are today considered indigenous, comprise an extremely closed environment requiring special solutions from those who wish to live here successfully in the long-term. Moreover, since the Evenki are a minority society with very little impact on representatives of majority societies in the outside world, modernisation can only come to them via the latter. For this reason, we shall begin the following study by attempting to describe the relationship between Evenki people and the state, which is quite ambivalent. This is perhaps also indicated by the fact that in certain places "Evenki had no knowledge of any Soviet power until as late as the 1950s" (Ssorin-ChaIKov 2003). During the Tsarist period, the state attempted to exercise control over the peripheral territories in the form of a fur tax. This taxation also constituted a law, but the approach could not have been entirely successful since the Evenki have maintained andaki, commercial ties with state officials as well as trade-oriented families of other ethnicities for centuries, a practice which continued throughout the Soviet system and still survives today. Another form of state control (Soviet) was to create and seek enemies in the region, searching everywhere for kulaks, shamans and early communist activists (who believed that Soviet power would make it possible for small ethnic groups to take control of their own fates). In the Soviet system, fear, terror and the division of local communities became the chosen instruments for asserting the power of the state.

During the early Soviet regime, nomadic Evenki were settled in villages under the heading of "Soviet culture". Children were obliged to attend school and forced to live in 
boarding schools while their parents worked. At the same time, the Evenki were provided with medical care; medical stations were established and pharmaceutical products were dispensed. Literacy programs and libraries were developed for them, and young people chosen as potential intellectuals could study at the Herzen College for Northern Peoples in Leningrad. Following the Second World War, during the early 1960s, a new age of "technical civilisation" began. Roads were built and electricity was installed wherever possible while the more remote regions of the inner taiga could be accessed by airplane or vezdehod (tracked vehicles). In these locations, diesel motors provided electricity for a few hours a day. Contact with the outside world could be established via hand-cranked or battery-powered portable radios (ratsio - in local Russian). The 1990s opened the world and brought along certain benefits of globalisation, such as Chinese lorries, Japanese excavators and Swedish drill bits, which, among others, can now be found in the Evenki land as well.

Tsarist Russia regarded the Evenki as being "outside of the state", which can also mean "outlaw". Even today, members of the majority society refer to them with expressions like "children of nature" or "last of the Evenki". In the course of her research in Indonesia, Anna Tsing reached the conclusion that everything outside of the state is also part of the state (Tsing 1993). Defining the Evenki as those without statehood implies a process of "nationalisation", and it is through the use of these terms that Evenki people became part of the Russian state. Soviet modernisation meant categories and privileges. The Evenki were shaped between the concepts of modernisation and tradition. They did not become big bosses or good citizens, and they did not regard all that was taking place in their lands as modernisation, but as the periphery of non-modernisation.

Hunter-gatherer Evenki have always maintained contact with the Russian (and later Soviet) state that wished to civilise them, settle them and connect them with the institutional system. The processes of decay that could be observed in post-Soviet territories when the state withdrew from the region during the 1990s brought both poverty and a temporary freedom in the life of Evenki people, some of whom enthusiastically began to engage in illegal activities, such as poaching or gold panning. Now, as we witness the return of the state, their anti-state practices have come into conflict with state attempts to control them through bureaucratic procedures.

\section{THE ANTHROPOLOGY OF THE STATE}

The works of Slavoj Žižek (among others ŽıžEK 1989), who in his turn referred to Jacques Lacan, inspired anthropologists such as Yael Navaro-Yashin to look at the attitudes of Turkish citizens to their state and analyse how fantasies about the reality of the state and cynical attitudes to its existence are interwoven in the everyday life of common people, who do not trust the state and simultaneously make no practical attempts to change it (NAVARO-YASHIN 2002). This cynical distancing from private activities as state citizens is one of the main instruments used by the state to maintain its powerful authority.

There are now two basic lines of argument developing with regards to the structure of state power and its distribution between its political centre and periphery. Some scholars, like Nikolai Ssorin-Chaikov argue that the centre/periphery dichotomy is itself a technology of state power and that concepts like stateless societies and tribalism are the 
results of exoticism (SsoRIN-ChaIKov 2003). David Sneath shows that the opposition between kinship-based orders and the state's organization of power relationships are misleading and are in themselves products of state political power (SNEATH 2007).

Other researchers suppose that the centre/periphery dichotomy and opposition are analytically significant. James Scott, for example, sees the state centre and its periphery as dialectical partners - opposite, but mutually related to one another. Anarchism is an inevitable part of life on the periphery, as is multiculturalism, in contrast to subordination and cultural unification. Historically, differences in landscape presupposed the distinction between easily controllable valleys, where it was easy to impose tax on rice and grain crops, and hills dependent on foraging, hunting and slash-and-burn farming, as in the case of South Asia (Sсотт 2009). Scott underlines that for hill dwellers resistance to the state was part of a continuous and conscious effort and that their anarchistic cultures were devoted to keeping the state at a distance, for example by the rejection of writing and through a disregard for histories and genealogies.

The assumption that all periphery dwellers consciously and intentionally resist the state or take refuge from it like guerrilla warriors, however, seems to be overly simplistic. It latently presupposes that any social organization, even one not integrated within the state, must inevitably be developed in relation to it, for example in opposition to it. As several anthropologists have shown, there are people who can live without the state, and even when the latter appears, their social organization continues to exist in kind of a parallel world. These are egalitarian societies of hunter-gatherers, who, according to Hugh Brody, are more connected with their place of habitat than any agriculturalist, even when leading a nomadic way of life. Moreover, this relationship to place (with its climate, annual cycle and ever-present changes and uncertainties) could not be mediated through the bureaucratic procedures of management by the central state (BRODY 2001). The egalitarian social organization of hunter-gatherers does not contain the pattern of subordination - obedience basic to the routine measures of state order. As shown in ethnographic work by Pierre Clastres (CLASTREs 1989), this difference between egalitarian social organization and state institutions is frequently interpreted by representatives of the state as a form of resistance).

The case of post-Soviet Russia is especially interesting in this debate because it has inherited the colonial structuration of territory in its central and peripheral zones, presenting the classic example of a state that is particularly dependent on resources (gas, oil, timber, minerals) which it cannot thoroughly control due to the sparse population and poor infrastructure in these territories. Being the main products for export, these natural resources became the basis for enormous fortunes amassed by new Russian elites, who launched their businesses in 1990s, when state control over the previously nationalised sphere of international trade weakened. These times were frequently described by anthropologists and sociologists as times of disorder and anarchy, when various forms of violent entrepreneurship developed both in the centre (VoLKOV 2002) and on the periphery (for example, Siberian province, HUMPHREY 2002). A new need for resistance to the state emerged after 2000, when representatives of this elite strata entered the peripheral zones of the Russian state with the aim of legalising their position (as when Abramovich became governor of Chukotka or to control local enterprises exporting natural resources abroad (as in the case of the nephrite business in Buriatia, which we will study in the framework of this project). All such movement from the centre to the 
periphery is seen as a return by the state because new authorities frequently try to obtain support from locals by rebuilding Soviet-style state institutions and programs, such as the distribution of cheap accommodation and the organization of summer vacations in camps for children (THOMPSON 2008).

There are two distinct things that could be called anarchy: stateless social organization not built on coercive central power and strategies for resistance to state authority. The former is applicable to egalitarian societies, such as hunter-gatherers, while the latter describes the actions of people who live in hierarchical societies but feel oppressed and unsatisfied with the proposed state order. Anarchism as an ideological movement was born in the framework of this latter endeavour, but very often uses the observations made in stateless societies as inspiration and in support of its arguments. Here we see two forms of anarchy which frequently overlap, but this does not mean that they are the same or even related to close phenomena: living without the state and living in opposition to the state.

As we have described elsewhere (SAFONOVA-SÁNTHA 2007) Evenki egalitarian social organization is also expressed in the socialization process. Children learn not to be afraid of aggression and violence. At the same time, there is no systematic punishment for misbehaviour, much less a clear idea of what misbehaviour is per se. As a result, when seven-year-old children leave their families and enter boarding school, they are already socialized individuals who do not fear the authoritative power of teachers, although they can pretend to be obedient in the event of any specific advantages arising from such a situation. In their villages, they are called hooligans, after which they start an independent life, no longer bound to their families to any great extent. Throughout their entire life, they carry a desire and inclination to be manakan (which in Evenki language means to be on your own path, autonomous and independent). While it is not possible for them to avoid all dependencies on other people, they prefer to establish various relationships at a time so as to avoid being tied to or concentrated on one particular person. The exception from this tendency is the establishment of conjugal units, spousal relationships, which are also very vulnerable and need to be destroyed and renewed from time to time in order to refresh them with passion and emotional tension. Aggression and drinking play important roles in this process. As a result of socialization in the frames of an egalitarian social order, an individual feels no inclination to behave according to commitments, obligations, roles and plans, but prefers to take spontaneous decisions, finding preplanned activities boring and unpleasant. This prevents the Evenki to fully integrate into state institutions. Moreover, exceptions such as the careers of schoolteachers and representatives of Evenki culture, who are integrated within organizations supported by state, usually entail unique biographical trajectories or even breaking off contacts with other Evenki people. From this perspective, it cannot be said that Evenki people consciously and intentionally resist the state, but their ethos simply does not fit into state institutions without disintegrating. Data from fieldwork shows that the Evenki very rarely criticize any local authority. On the contrary, they support state policies and try their best to integrate within them, but something always goes wrong. As a result, however beneficial any state initiative might be to the Evenki, even if it is seemingly unplanned and the Evenki themselves appear to like it, in practice they always appear to be excluded from the scope of such reforms and measures. Collaboration with state representatives never turns out to be profitable for the Evenki, in contrast to their short term companionships with those who were involved in illegal and anti-state activities. 
Evenki people are living on the periphery of the Russian state with other people who have escaped there from state policies, were sent there by the state in frames of prosecution or who moved there in search of profits from illegal activities (poaching, illegal gold and nephrite mining). These people represent various cultures and therefore no abstract or unifying code of conduct and meaning can be used to coordinate their actions. Consequently, short term relationships devoted to the implementation of concrete projects frame most of the interactions among people who live in this territory. Evenki social organization provides a useful matrix for them to collaborate with various neighbours and establish short term contacts, and these are especially important in emergency situations, which are rather frequent in the taiga environment. Contacts and interaction in the taiga are situational because in cases of crisis there are no other possible partners available for hundreds of kilometres. No outside expectations, social distinctions or superstitions are important when there is imminent risk of freezing to death or drowning while attempting to cross a mountain river. Everybody who appears in the taiga must display egalitarian character to some extent, otherwise they will be in trouble. The introduction of new technologies here does not help one to obtain a superior position, because no technology is secured by accident or as a result of malfunction. The taiga as a place which attracts various people with its resources (herbs, wild meat, antlers and skins, fur, timber, gold, nephrite and so on) forms a special interactional environment in which even the representatives of hierarchical societies have to behave according to patterns of equality.

\section{METHODOLOGY}

This study is devoted to a detailed analysis of patterns of interaction in the everyday life of Evenki people, with particular focus on nonverbal forms of communication. Due to this focus, the research methods of anthropology, such as participant observation and interviewing, are supplied through the collection of visual materials, such as photos and film records, which will form the main data within framework of this research project. These materials will be used for analysis and coding, which will help to formulate categories that describe the main forms of non-verbal communication and the coordination of actions in everyday life. Ethnographic methods based on observations and fieldwork notes usually leave such information off the record. Systematic filming and photographic recording help to document instances and moments of interaction which are impossible to describe in the framework of verbal ethnographic accounts (reports based on field notes).

In 1942 the world anthropological community was provided with one of the most outstanding results of anthropological fieldwork - the book presented by well-known anthropologists Gregory Bateson and Margaret Mead about Balinese character (BATESON - MEAD 1942). The book contained 100 charts and more than 700 photos selected from 25,000 Leica negatives made in the course of their collaborative fieldwork in Bali. Photos played the main role in the book and were organized according to categories, which anthropologists elaborated during the coding and analysis of their visual data and ethnographic field notes. The book became a classic handbook for visual anthropologists (such as PINK 2007), but also raised reflexive feedback both from anthropologists 
(GRIMSHAw 2001) and researchers from other social sciences (SILVERMAN 1993). The attempt was a success according to most reviewers and was then repeated by Mead in collaboration with Macgregor (MEAD - MACGREGOR 1951), although this was more an illustrative work in which the authors described the pre-existing categories that were used in psychological theory with photos taken by Bateson. Later, Gordon Jensen and Luh Ketut Suryani repeated the project, retaining the structure of the book that Mead and Bateson used in 1942, but they used other categories and even tried to re-examine and criticize the earlier interpretation of Balinese culture (JENSEN - SURYANI 1991). Critical and supportive discussions very often are supplied by materials collected from fieldwork in the same areas, where the authors of classical manuscripts worked.

The most famous examples include the refutation of Mead's work on Samoa (MEAD 1928) by Derek Freeman (FrEEMAN 1983) and a less scandalous study of Naven rituals among the Iatmul, conducted by Michael Houseman and Carlo Severi (Houseman SEVERI 1998) after Bateson (BATESON 1958 [1936]). Attempts to conduct similar research with explicit associations in methodology and theoretical background, but in other areas, are much rarer. In our research, we have conducted photographic analysis according to the logic and scheme employed by Bateson and Mead in 1942, but based on materials collected in the present day among Evenki people, modern hunter gatherers living in Siberia. The research methodology proposed by Mead and Bateson seems to be very effective for the study of the Evenki because it provides the opportunity to include nonverbal elements basic to this egalitarian society, both at the stage of analysis and in the representation of the results.

From September 2008 to November 2009, we worked among Evenki people at three different field sites in Baunt in East Buriatia. We spent the autumn of 2008 and the first half of that winter in the Evenki village of Ust'-Jilinda. In the middle of the winter, we moved to Ilakachon and stayed there until the spring to study the life of an isolated reindeer-herding Evenki community. During the following summer and autumn, we moved to another Evenki group living near the Taloi and Kudur rivers. These Evenki people were maintaining contact with nephrite miners for the majority of the year. István Sántha had visited this region and conducted two months of fieldwork there for the first time in 2004. When we started our fieldwork, the aim was to write a book about the situated non-verbal aspects of Evenki culture, which would be based on an analysis of video and photographic materials. Tatiana Safonova worked with a simple KonicaMinolta DiMAGE 23 digital camera in the autumn of 2008 and the spring of 2009. Then she changed to a Pentax K1 mirror reflex camera, equipped with a normal 2/35 millimetre Pentax digital objective. She shot black and white photos with the Konica-Minolta and then made colour pictures with the Pentax. István worked with a Nikon-FM2a, using a normal 1.4/50 millimetre Nikkor manual objective and Kodak Elitechrome slidepositives. Tania mostly shot photos around campsites while István Sántha worked more in the taiga. Altogether, they took around 14,000 negatives and 3,000 slides, respectively, during this period. Besides taking photos, we also wrote diaries and created videos (almost 100 hours in total). We tried to shoot photos randomly in order to collect a wide spectrum of materials not restricted by strong preconceptions and so as to analyse them afterwards, providing a chance to recognize things that were not noticed in the field.

The total of 17,000 photos were analysed via selection and categorisation. The possible situations that occur in Evenki land have a so-called emic (Evenki) logic of 
development. These logical serials as reconstructed through photos were significant in examining the flexible (and situated) culture of modern Evenki hunter-gatherers in terms of new technologies.

Before presenting the charts with selected photos explicating particular categories, we would like to discuss a character of scientific investigation first mentioned in anthropological studies by Gregory Bateson (BATESON 1979:210). The analysis moves forward on a zippered path between data and abstract interpretation. In our case, as in the case of Bateson and Mead (BATESON - MEAD 1942), photos were the starting point, after which the titles of plates appeared, which in turn practically became main categories. Later, we wrote about the relationships between photos and the details in each photo, and finally we gave descriptions of the relations between plates, the latter of which could also be accepted as summaries. 


\section{A PHOTOGRAPHIC ANALYSIS}

\section{New means of transport}

Being nomads, the Evenki are very interested in every possible means of movement and travel. New transportation creates an opportunity to move faster and to carry larger loads. These new capacities change the world of the Evenki because, as they are able to carry more with them, they can possess more in general, and if they have more things, it makes their life more stable, localized and less nomadic. New types of transport bring new kinds of dependencies upon the outside world. The other aspect of this dependency is the fact that new transportation is neither capable of crossing great distances in the taiga, nor cheap to exploit independently, so the most expensive means of transport are controlled by outsiders and the Evenki cannot use them in their own interests. Older forms of transportation, such as reindeer and horses, are still kept by the Evenki, although they are not used as extensively as they were prior to the integration of cars, all-terrain vehicles and tractors. Even so, until such times as these new means of transport are totally controlled by the Evenki, their life in the taiga remains impossible without horses and reindeer.

Figure 1. Chinese wheeled tractors, specialized in nephrite mining, have been bought by the local Evenki community and given to several Evenki families. These are mainly used to carry tree trunks from the forest to the camp. Winter is the only season when these machines do not stick in the mud.

Figure 2-3. Old all-terrain vehicles are bought from military camps by the same Evenki community and are mainly used to transport nephrite from the mine to the city. The Evenki travel with these tracked vehicles when they go deep into the taiga to work there as hunters for the community. Every week, several such vehicles stop at the Evenki reindeer camp situated halfway between the nephrite mine and the last village. Here the drivers and the security have a short rest. The majority of the food supply of the reindeer camp is also transported by these all-terrain vehicles.

Figure 4. It is only possible to use vehicles such as the jeeps in winter, and only along the frozen rivers, which in winter look like polished highways.
Figure 5. Horses are still the most popular form of transport. They are even preferred by the reindeer herders, who use them to transport things between their summer and winter camps. However, they need all-terrain vehicles for the main seasonal removal, because horses cannot carry all of their bulky and heavy possessions. Horses are nevertheless indispensable in hunting.

Figure 6. Reindeer are now very rarely used, but there are still places where they are the only form of transport for the Evenki. People do not ride them anymore, which makes traveling with them less convenient. People have become taller and the reindeer have become smaller.

Figure 7. Aeroplanes still fly to the isolated villages of the region, but the tickets are too expensive. Ordinary flights are rare because there are seldom enough passengers willing to buy tickets, but medical emergency flights take place and local residents always try to take advantage of the opportunity to fly with these aeroplanes for free. 

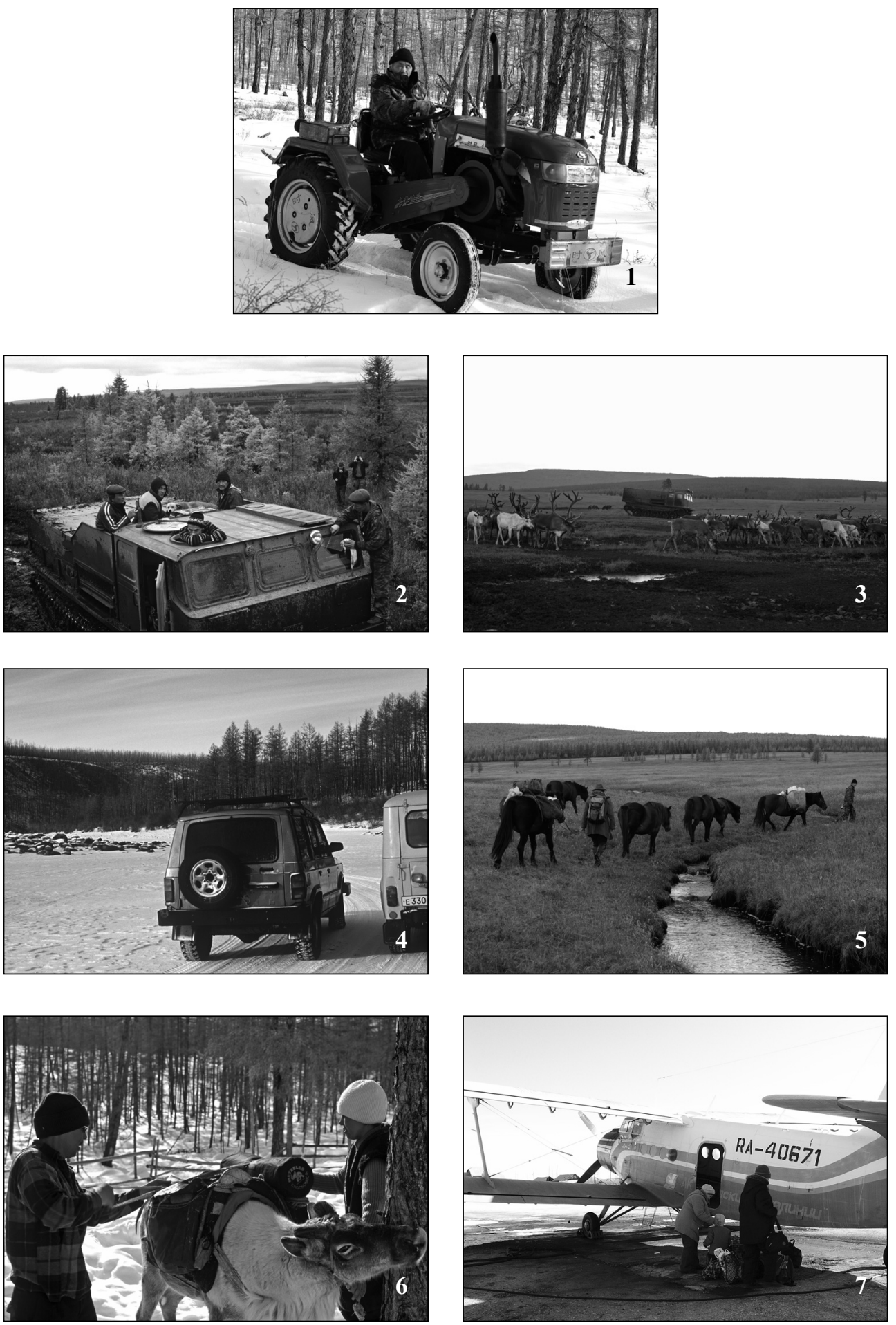


\section{Combining new technologies}

The introduction of any new technology brings about such changes in the amounts and quality of task accomplishment that it is impossible to combine such technology with older technologies with lower capacities. Usually, new devices are connected to each other, so one thing changes the entire spectrum of various tasks and creates a need to introduce other new technical equipment. Unless they are combined with other new equipment, these innovations are excluded from the existing web of older technologies, and cannot be integrated into everyday life at all.

Figure 8-9. The use of petrol-powered saws makes no sense without a tractor due to the number of trees that can be cut down and then need to be transported to camp. Such saws usually enable people to cut more than they did before and, as a result, they need to go deeper into the forest for new trees of the required quality. Longer distances and greater amounts of lumber determine the need for tractors.

Figure 10-11. All-terrain vehicles have brought with them the possibility of various new forms of hunting. For example, the hunter can travel at night and use lights to find wild animals. Paralyzed by the light beams the night, animals are not able to run away. They run along the track of the beam because they can see only parts of the terrain that are lit. It is very easy to kill such helpless creatures. But the use of lights at night is impossible to combine with traditional hunting transport such as horses. Horses do not work well at night and there is no transportable power supply for the lamps. Even in the event of success, the hunter will not be able to transport all the meat because hunting with lights usually provides the opportunity to kill several animals during one night. In Figure 10 the hunters are constructing a lamp that can be operated manually. Figure 11 shows a hatch in the roof of the vehicle, through which the standing hunter can use the lamp and then shoot the animals that are caught in its beam.

12-14. Binoculars are not an absolutely new thing for the Evenki. They have been used ever since the Evenki acquired guns with a longer shooting range. New guns have an even longer range, and they are supplied with telescopic sights. This is important because animals that are seen from a longer distance need less time to escape, and the hunter has less time to switch from the binoculars to the gun sight in which he needs to find the animal once again. These two technologies, connected with sight and shooting, always predetermine each other. 

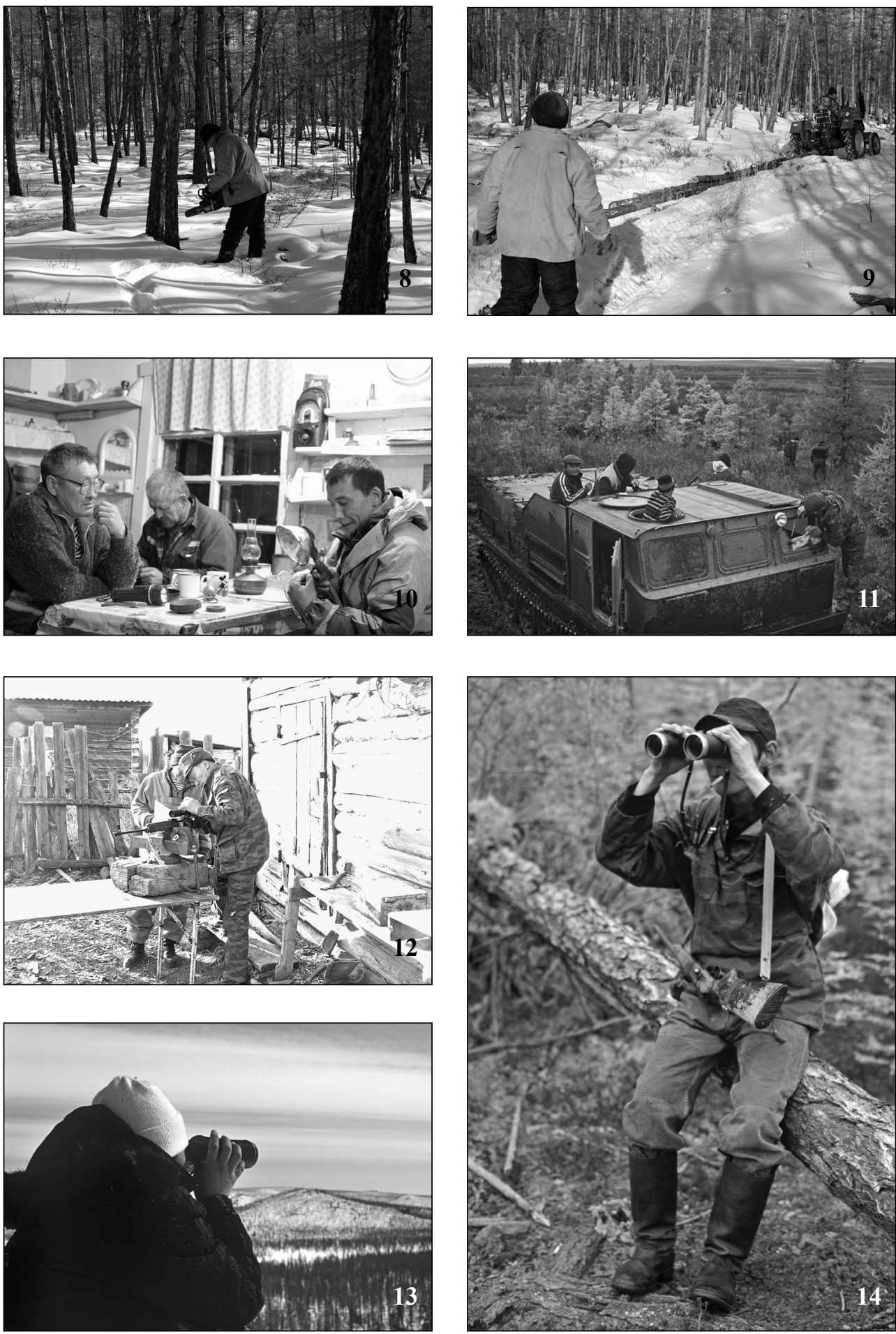


\section{Parallel old and new technologies I}

Although new technical devices are generally not compatible with old ones, they do not supplant old technologies at all. Old technologies may be less productive, but they are much more reliable, and so they continue to be maintained as reserve options, which are important in the frequent cases of emergency, when new devices break down or there is no petrol to run them. Life in the taiga and isolated villages predetermines such episodes of crisis for new technologies, which can only be repaired or supplied through contact with the outside world, and such contact is not possible for extended periods of time. Simultaneously, the introduction of new technologies presupposes the support of older parallel ones, even if these older ones were already out of practice and nearly forgotten. In this process, the progress of technology goes hand-in-hand with the reminiscence of older, more conservative elements of culture. As a result, the only new technologies that persist are the ones which have parallel options from the traditional repertoire of Evenki culture. Even though the practical accomplishment of everyday tasks changes and develops, the general cultural matrix of everyday tasks remain the same.

Figure 15-18. Evenings allow time for leisure and relaxation. Watching films has become an ordinary evening practice, which can be replaced by reading books and journals in the event that a diesel generator fails. And here the oil lamp helps to resolve the problem of lighting. Figure 17 shows one of three diesel generators that belong to an Evenki family living at a reindeer camp. Sometimes, even all three of them are out of commission, or there is not enough fuel to start them up. The Evenki sometimes travel to nearby winter huts for hunting and are not able to take diesel generators with them. In both cases, oil lamps are used in the evenings.

Figure 19-20. At the reindeer camp, the Evenki use a water pump installed in an adjacent river and supplied with energy by a diesel generator. However, in an isolated village the Evenki need to carry water themselves, in buckets and other containers because the river is too far away from the house. At a reindeer camp deep in taiga, the Evenki even keep a small garden, which they water using these tools. But the products from this garden do not play a crucial role in their diet, and so the Evenki do not depend upon or care too much about it. The pump makes their life easier, but they always maintain the possibility of carrying water themselves.

Figure 21-22. In an isolated village, the only way to be connected with people from other villages is to use a satellite phone, which is installed in the local administration building. This telephone uses Russian satellites, which are not very reliable, so the signal is frequently too weak to establish a connection. The telephone needs electricity, which is supplied only during certain hours when the village diesel generator is working. People are accustomed to this instability of phone connection and use it more as a form of entertainment than as a regular communication facility. In a distant reindeer camp, where there is no satellite phone and people live for more than half the year without any news from their relatives, they use alternative ways of connecting with them, such as divination and the reading of cards. 

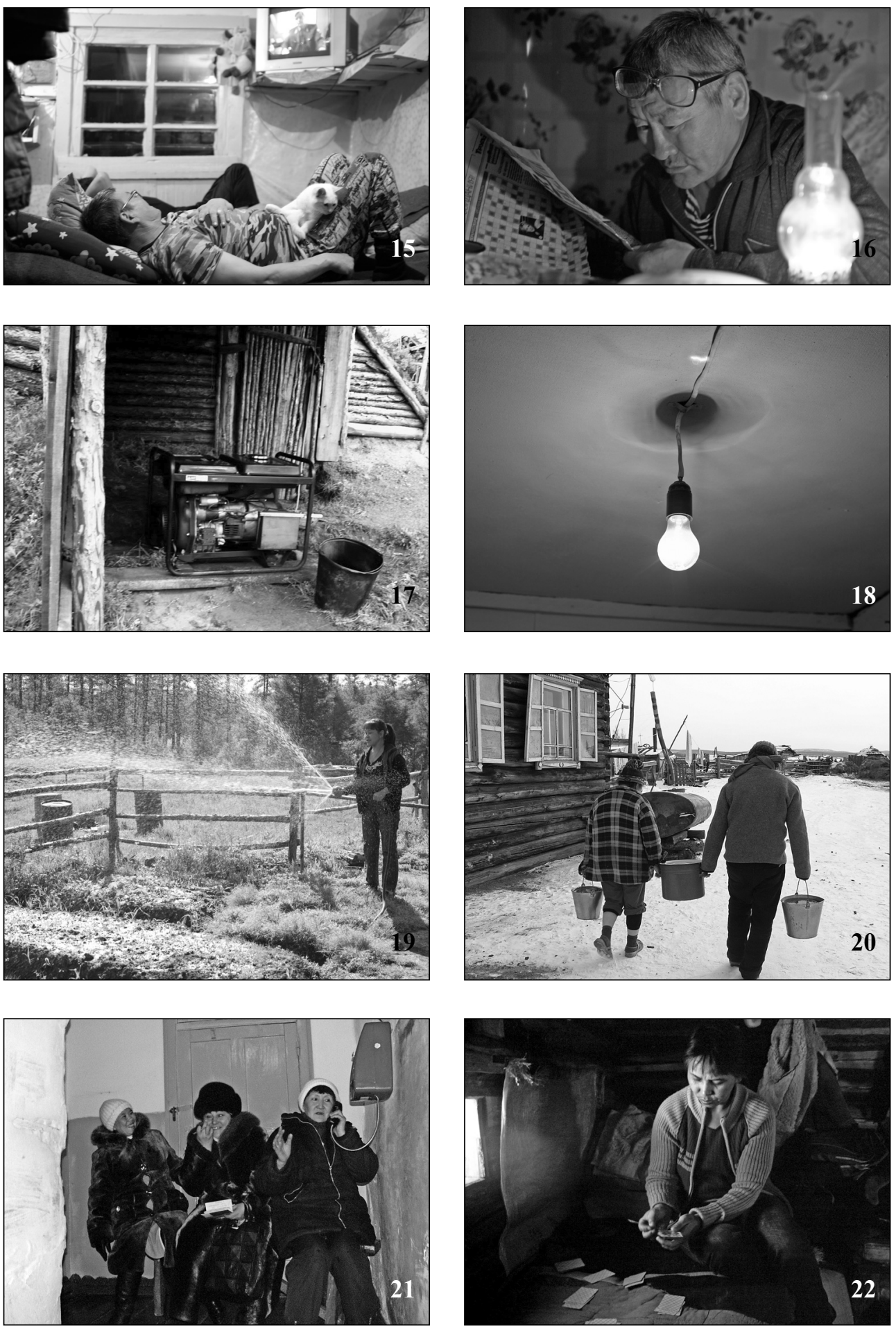


\section{Parallel old and new technologies II}

All old technologies once were new. Over time, as they become more inevitably embedded in everyday practice, the coordination of activities among different parties involved in them slowly changes from a complementary to a symmetrical mode. This means that all people gradually learn how to use the technology and the position of a specialist and introductory sponsor is eliminated. At the same time, the growing dependency on the products of the technology requires the equal mobilization of all members of the community. The parallel coexistence of new and old technologies also plays a role in maintaining the balance between complementary and symmetrical relationships between people. Situations of affluence and comfort associated with a complementary mode of action are counterbalanced by emergencies, when symmetry is the only way to mobilize all members in order to overcome difficulties.

Figure 23-24. One person is operating a petrol-powered saw, while the other person is directing the fall of the tree. The new technology has predetermined such a complementary distinction between the roles of the involved actors. The two-handed manual saw needs the equal force and involvement of two persons, and the cutting is not so fast that people cannot at the same time direct the fall of the tree. Their involvement in the task is symmetrical.
Figure 25-28. Tractors or all-terrain vehicles are driven by one person, while the other acts as navigator, steering a safe passage between the trees, or checking that the trunks are stoutly bound together. Transportation of the trunks without vehicles requires the work of all members, both men and women. In Figure 26 the figure of a woman stands slightly aside, watching as men drag the sledge laden with trunks out of a gully in the snow, but in the next moment she seizes one trunk, puts it on her shoulders, and carries it the whole way home like the others. She also carries an axe. 

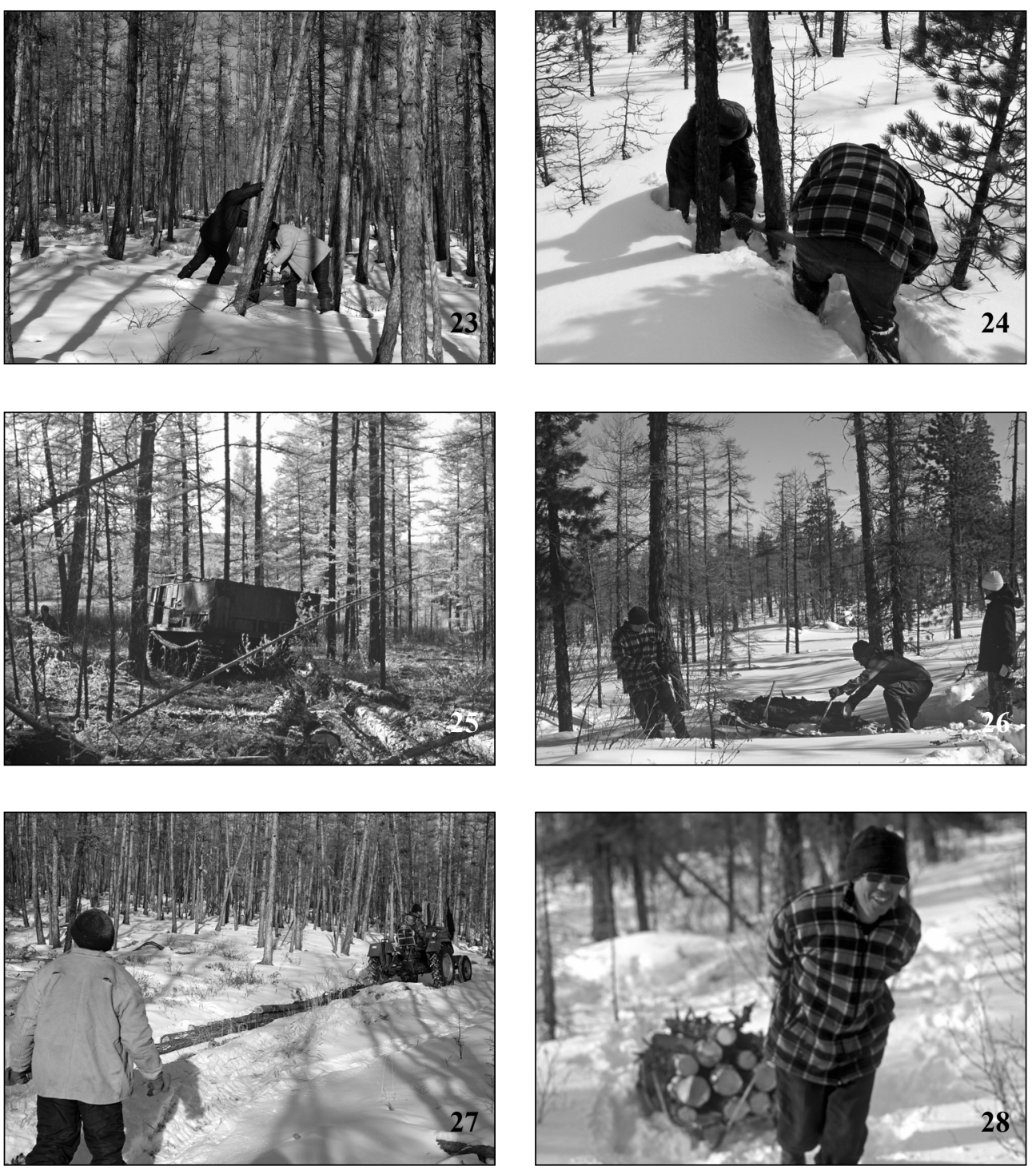


\section{Repairing technical devices}

Repair work is a task in its own right, more frequently connected with just passing the time or simple curiosity than with the practical installation of a device. If something is easily broken and too complex to be repaired over the course of an evening, it is usually dropped from the set of equipment in active regular use within the household and for years can become a focus of the owner's curiosity and attempts to repair it, without any apparent regret that it is not working anymore. This practice becomes part of a special kind of leisure. Repair is also a step in the process of sorting out, when unreliable and fragile new technologies are rejected. The Evenki rarely discard things. They prefer to combine them, exploring all new and possible options. From this point of view, repairing an item is one way to not openly exclude it by throwing it away, but to find a new function for it within the household, at the very least to make it a toy to be played with in leisure time. For this reason, the Evenki do not try to systematically understand a given device and its workings, but simply attempt various combinations of actions, hoping for the chance that somehow it will work. As a result, these manipulations more often than not lead to the definitive destruction of a mechanism. Knowing this, certain persons in the household, for whom the function of the device is somehow important, prevent all attempts by others to repair it, trying to save it in its original form before seeking external assistance from the outside world.

Figure 29-30. Whenever Semka was free, in the evening or daytime, he would try to repair a radio that originally would have been powered by a compact solar battery. As the wires were so mixed up and cut at several places, it was obvious that Semka was clearly not the first person to have attempted to repair it. Yet Semka persisted and did not abandon the task, returning to the radio from time to time.

Figure 31. In this picture, Nikolai Stepanovich is trying to fix a car, which he managed to doom on this occasion. It later broke down while being driven far from home and had to be left where it was. The fate of the car is unknown to us.

Figure 32. Sometimes assembling something from various parts, its maintenance and repair are all part of the same process, endless and embedded into the practice of usage. This is especially true for illegal devices, such as uncertified guns, which it is not possible to obtain and repair openly. In practice, these semibroken items are usually deployed as alternatives to normal mainstream things, but they take a lot of time and attention from their owners.

Figure 33-34. Machines that need starting up (such as tractors or generators) are always at risk, because any unsuccessful attempt to start them can initiate a consequent attempt to repair them.

Figure 35-36. If a device is not easily repaired and the possible various combinations of obvious actions have been tried without success, then the Evenki usually try to resolve the problem by force. This usually leads to additional breakdowns. 

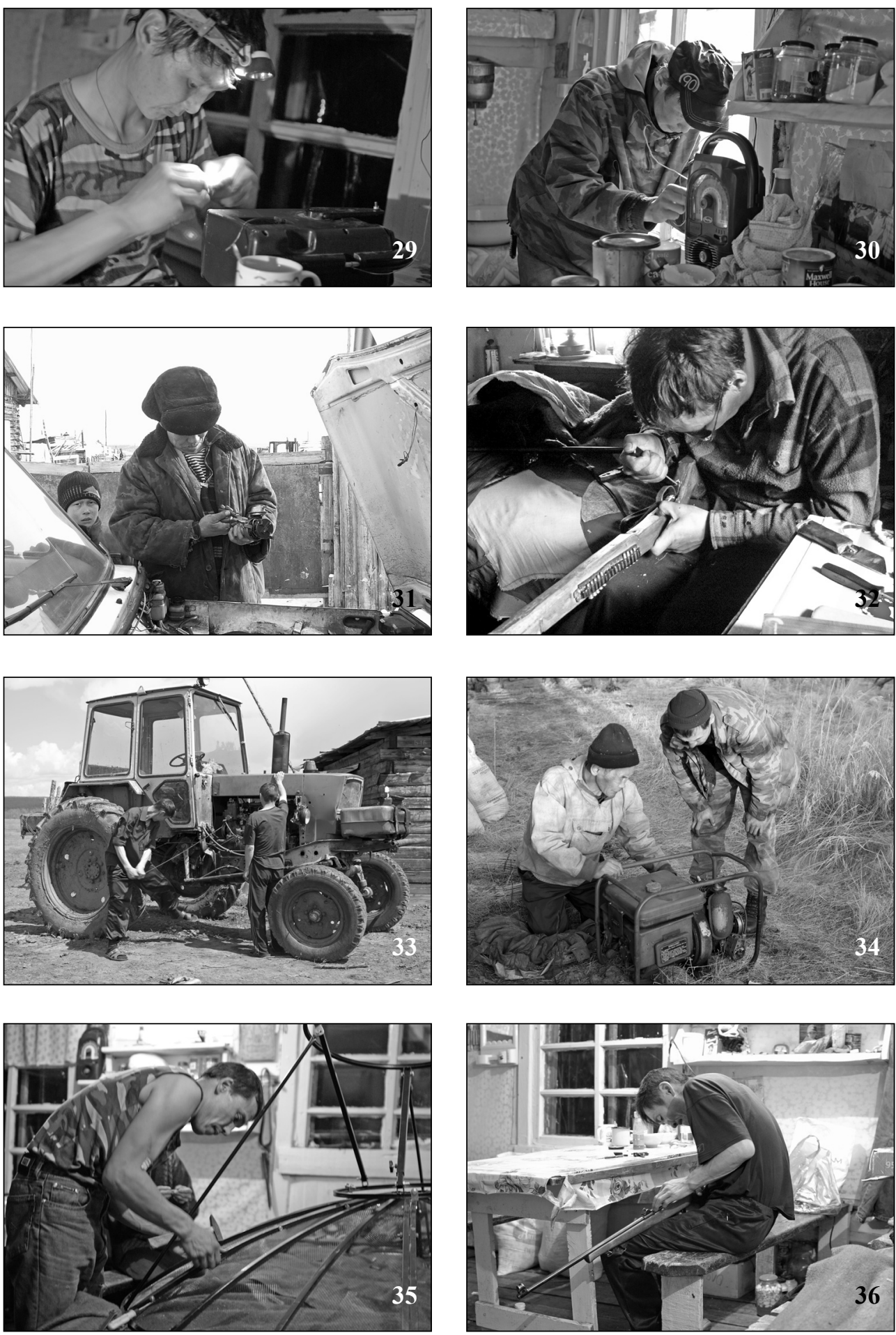


\section{New visual technologies}

Leisure as a sphere that is not connected with survival and its production contains less risky situations and fewer potential emergencies; consequently, it provides more options for the integration of new and experimental technologies. Modern leisure technologies are mainly represented by various visual devices, such as televisions, computers and cameras. This sphere is dominated by play as a mode of action; and it attracts children in particular. Although these technologies do not depend so much on parallel old technologies to find a place in the Evenki ecology of tasks, their position is also unstable. This is largely because all new modern visual technologies presuppose intense and constant connection with the internet, or with television frequencies, or with mobile telephone frequencies, or with program upgrades. The isolated Evenki life, with its incidental contacts with outsiders, does not provide such stable interconnections. Hence, the only new visual technologies associated with leisure which find their place in Evenki life are those which presuppose only accidental contacts with the outside world. Very few modern visual technologies meet such criteria.

Figure 37. Children combine their playing with toys and watching television like adults combine various technologies and tasks with each other.

Figure 38. A lively party is frequently accompanied by a switched-on TV, which is usually watched by children who are excluded from the adults' feasts. At the same time, its noise creates an atmosphere of revelry.

Figure 39. In the computer games that Maxim is playing he is firing in virtual reality. In his real life at reindeer camp he has his own gun and is learning to shoot at targets. He is preparing to become a hunter like his father. The computer that he plays with in the village is at risk because it can easily be infiltrated by viruses. Anti-viruses programs do not help much because there is no connection to the internet to upgrade their databases.

Figure 40. The Evenki have to repeatedly watch the same films in their DVD collection because they cannot install a satellite antenna. Even if they had one, they have no access to a specialist with the expertise to be able to properly orient it to work at their distant reindeer camp.

Figure 41-42. Showing photos is a common practice when receiving guests, but the Evenki also like to privately view them from time to time. The photos they collect mainly represent the history of their contacts with other people. They cannot print the photos they would like to and are restricted to only those that are given to them by visiting outsiders. 

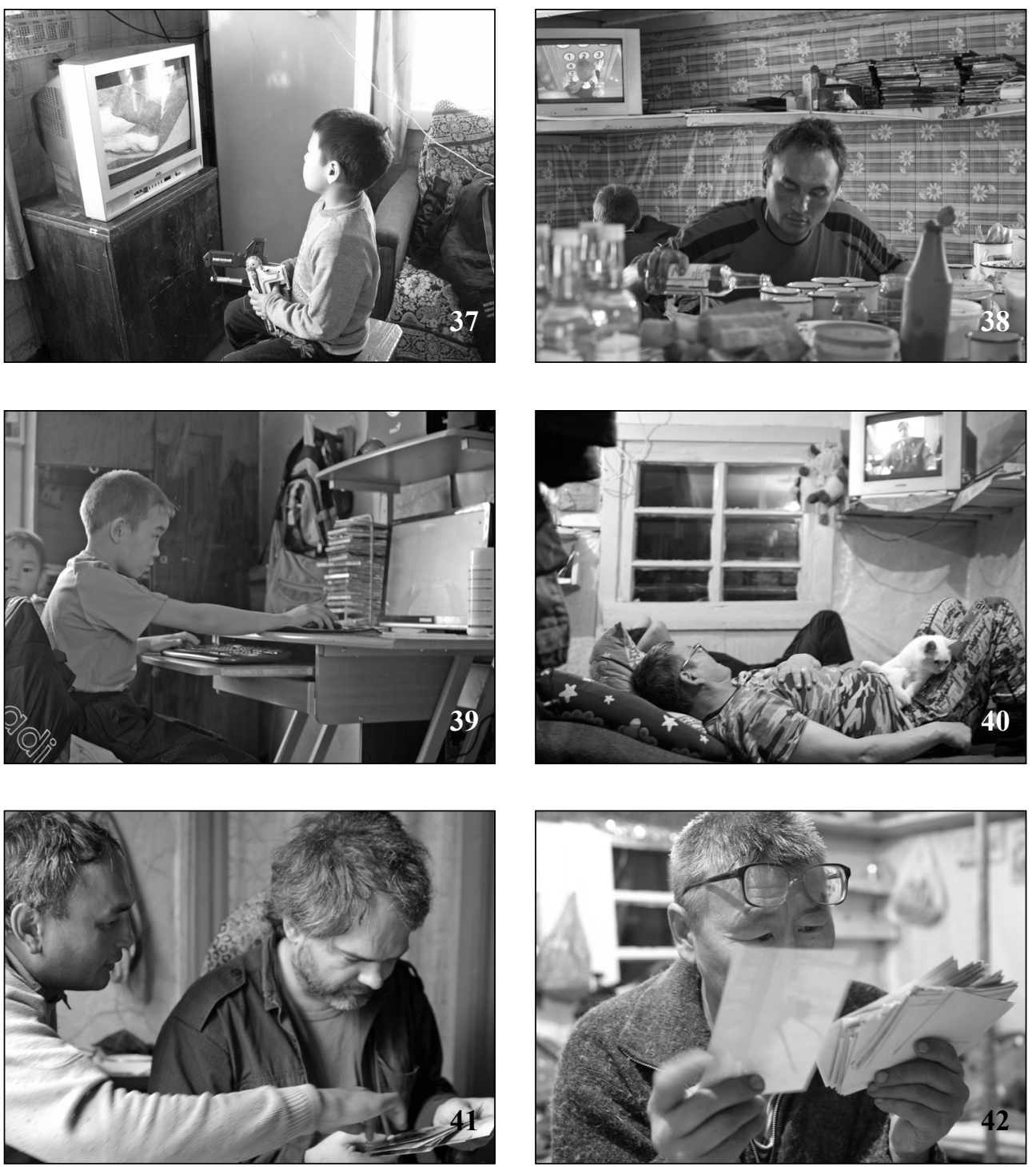


\section{Integration of new technologies}

The Evenki are simultaneously curious and very pragmatic. They are interested in how new things can be used and are open to all the new possibilities that new technologies bring. When a new technical device appears, they first try to integrate it into existing schemes of technology. If the device fits into the pre-existing niche, it frequently maintains this concrete function in the Evenki household. Consequently, new technologies are adjusted to the Evenki way of life and change it more on a quantitative rather than a qualitative scale.

Figure 43-44. Andrei is playing with our video camera. He has accommodated it very quickly to the habitual practice of seeing through binoculars.

Figure 45. Binoculars are a common instrument, which Andrei uses when searching for reindeer.

Figure 46. Maxim also found the same function for the camera without our assistance. He also liked the zoom function, which resembled the telescopic sight of the gun used by his father.

Figure 47-48. Looking at the world through an artificial sight is a common experience shared both by women and men. The adjustment of a gun also presupposes several attempts at searching through a sight before firing. 

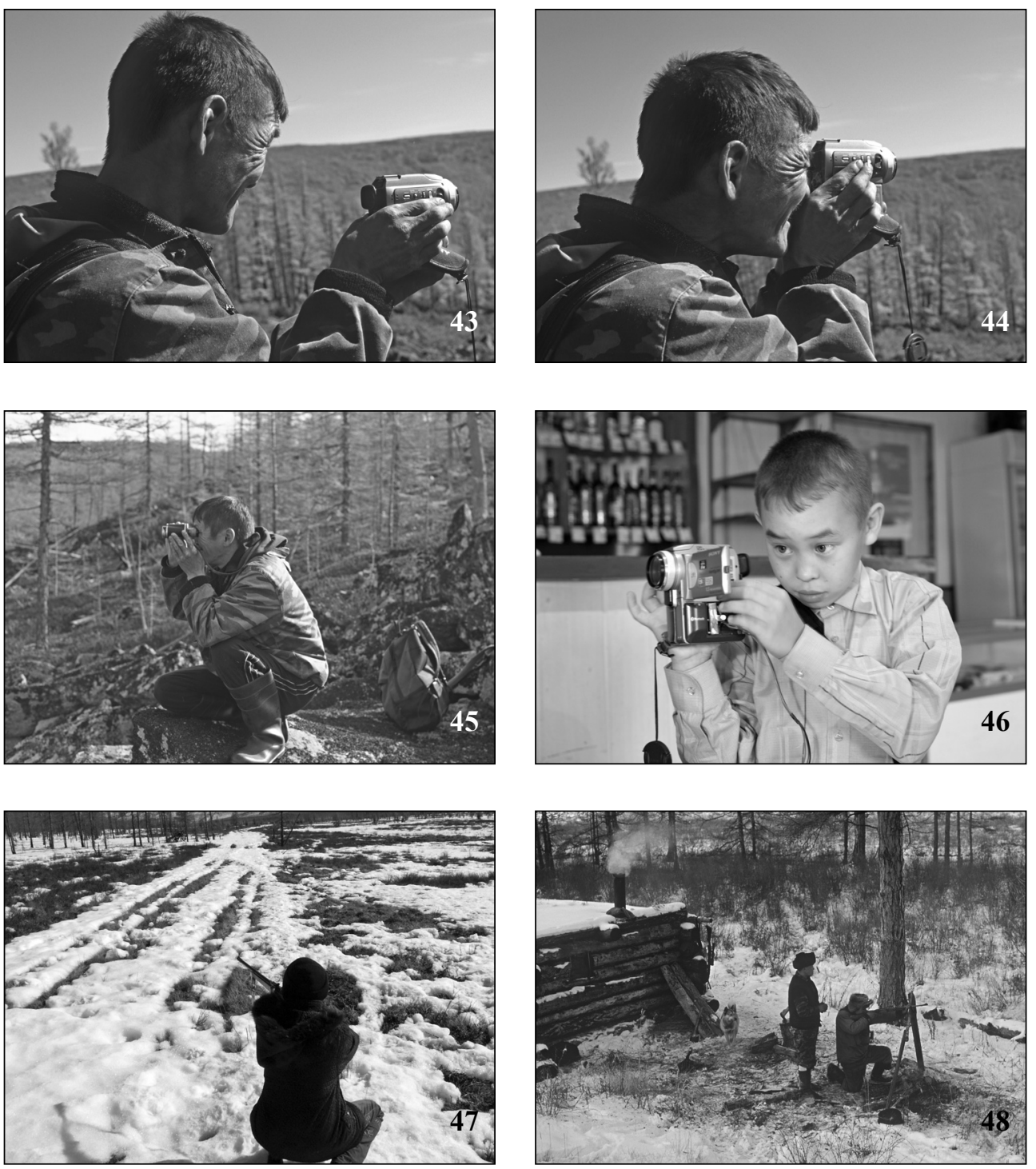


\section{MODERNITY AND EVENKI CULTURE}

In conclusion, we will attempt to systemise our experiences in connection with our photographic analysis. Firstly, we have found that there are certain decisive activities among the Evenki peoples of East Buryatia that can be considered tasks in light of their peripheral circumstances and their natural environment. Such activities include, for example, transportation. This already reveals that modern and traditional technologies exist together in the taiga. Such tools comprise pairs. New and old technologies are connected to one another. In the course of our analysis, we reached the conclusion that modern technologies which survive are the ones that can be coupled with traditional counterparts. In Evenki lands, there is never a guarantee that a (modern) technology will be continuously and regularly used, and for this reason it is not possible to ignore the use of older tools as alternatives. When a new tool appears among the Evenki, it gives rise to a category which includes an older technology. Such pairings reinforce the necessity of the old-new dichotomy and the importance of the categories - activities - tasks associated with it. We believe that the survival of certain elements of Evenki culture are primarily served by the appearance of a new technology in keeping with this dichotomy in the daily life of Evenki people. As István Sántha has also experienced with the Evenki in Tutur, a practical revival of old solutions is required from time to time. When a young hunter started the hunting season in the autumn and discovered that the cabin in his territory had collapsed, he spent no time lamenting and immediately set about constructing a shelter made from bark, where he lived for the rest of the season. He was even able to do this with no previous experience of how to construct a birch-bark tent. The existence of tools such as wooden hunting cabins, which have been common to the region for more than 30 years, does not completely omit the possibility of using an older alternative like a birch-bark shelter. Items that have no modern counterpart, such as the kumalan, rugs made from reindeer fur that are used to hold saddles in place, thus become decorative objects or gifts and are slowly disappearing from Evenki culture.

In addition to the above, I should also point out that the majority of modern technologies can only be used by a single person rather than by several individuals simultaneously, and since the Evenki society is adjusted to poverty, it is no surprise that only one of a given item exists within a community, which in turn requires specialisation and a division of labour. Of course certain devices eventually become commonplace, with more and more people using them in their daily lives. Tools once considered modern do not always remain new either - after a time, several of them may be in use, just as old devices used today were once regarded as new. For the Evenki, old technologies (which used to be new) provide a comfortable opportunity for symmetrical activity (wood-cutting with handsaws, or the transport of logs with small sleds). In analysing data referring to the $18^{\text {th }}$ century, Shirokogoroff already concluded in the early $20^{\text {th }}$ century that Evenki culture would disappear within a short space of time (SHIROKOGOROFF 1929). How then has it been possible for Evenki culture to survive for centuries? Evenki culture is protected from the impact of modernity by the fact that its practice requires symmetry in the context of activity in order to survive, which means that Evenki society does not accept all complementary technologies from the outside world without reservation. On the other hand, after a time it is also capable of turning the complimentary approach required by the usage of modern tools into symmetrical activity. It should be noted here that without 
the complementary impact of the outside world, Evenki culture based on symmetry (equal relations) would disintegrate. The balance existing between the complementarity and symmetry (BATESON 1958:289-291) suggests that Evenki culture is able to survive in spite of the impacts of modernisation (SAFONOVA - SÁNTHA 2013:26-27). This leads us to the concept of a self-regulating system. Our conclusions below call attention to the detailed operation of this system.

Various combinations appear either among new technologies or among old ones. We found no photographs suggesting a combination of an old tool with a new one. The matches reinforce one another. In the case of new tools, for example, this takes place when one element in a given pair fails, after which the Evenki gradually search for a new item to ensure that the given combination continues to function successfully. New pairs are matched with old pairs designed to fulfill the same task, the elements of each pair being in a complementary relationship. This gives rise to the question of whether original new combinations can be adapted successfully among the Evenki without replacing an older (alternative) pair. There are no real examples of this - if the diesel motor stops functioning, the tea-maker will also become useless.

Devices continue to function until the Evenki become interested in their principles of operation. Experienced, older Evenki do not allow curious children or adults near a highly revered new technological device. The disassembly and reassembly of things demands consistency (a logical approach), which does not appear as an interesting task for the Evenki. This makes it easier to understand why the repair of devices can be regarded as an everyday leisure activity rather than a task requiring strict focus. The aim is not to repair something; we have seen many instances which reveal a lack of understanding with regards to the operating principles of a given device. Instead, the Evenki try to examine how a faulty instrument can be combined with another tool so that both can be used for something together. The Evenki have experienced that all things go wrong sooner or later. For them, trying to identify how and for what purpose a faulty device can be used again is a process of creativity. Practice has shown that the tools of modernity that appear from the outside world can only be repaired in the outside world. In this way, the Evenki see modern tools as a means to make contact with strangers, other people and the outside world.

Some tools of modernity (new visual devices) - in addition to the need for transportation, firewood, water, food and contact with strangers - serve to provide a solution for another, non-active task: spending leisure time and resting. The use of such devices is not rooted in the practice of using older tools and only works through the combination of many new elements. There is no need to understand how they operate in order to use them, and as the above has shown, Evenki creativity may even prove to be extremely dangerous in some cases. While children are enthusiastic about such devices, adults appear quite passive in the course of using them, and since their usage does not have to be integrated with the taiga, they demand the creation of a modern environment in which to operate. As such, it is difficult to regard these tools as part of the Evenki sphere, belonging rather to a sphere in which strangers feel at home and hence providing a field of cultural contact within the taiga. They are used in the context of temporary episodes and their periodical absence does not endanger Evenki culture.

As the Evenki become familiar with new technologies appearing in their environment, they attempt to use these tools in ways that fulfill familiar (old) tasks. They try to 
understand what the tools are designed for and the situations in which they can be used successfully in accordance with their own categories (traditional ones) rather than those of the outside world. A video-camera can be a weapon as well as an optical device (telescope). At first, there is a tendency to move in the direction of complementarity, but use of a given technology only survives among the Evenki if the temporary phase (visual devices) can also be followed by the application of symmetric contacts. It is for this reason that Evenki society, organised on the ethos of equality, needs to find a balance between complementary relations and the hierarchical outside world based on specialisation. This is both a fundamental requirement for survival as well as for the successful integration of modern technology in Evenki society. A clear sign of the latter is when usage of a given technology becomes common and the technology becomes widely available. This is an especially crucial point among certain Evenki groups, for example those in Ilakachon, who have lived in total isolation for six months out of the year since the economic crisis forced the withdrawal of foreigners from their region. Their life is characterised by a lack of complementary relations. The same is even true in the case of Evenki in Kudur, who are in regular contact with nephrite miners for the majority of the year (SÁNTHA 2011), and through whom they are able to gradually incorporate modern tools in their everyday lives - certain intervals notwithstanding (late October to early April), when they remain isolated in the taiga and practice Evenki-style symmetric relations with one another.

\section{REFERENCES CITED}

BATESON, Gregory

1958 Naven. A Survey of the Problems Suggested by a Composite Picture of the Culture of a New Guinea Tribe Drawn from Three Points of View. Stanford: Stanford University Press.

BATESON, Gregory

1979 Mind and Nature. A Necessary Unity. New York: E. P. Dutton.

BATESON, Gregory - MEAD, Margaret

1942 Balinese Character. A Photographic Analysis. New York: Academy of Sciences.

BenNeTt, Jane

2010 Vibrant Matter. A Political Ecology of Things. Durham - London: Duke University Press. (A John Hope Franklin Center Book.)

BRODY, Hugh

2001 Other Side of Eden. Hunters, Farmers, and the Shaping of the World. New York: North Point.

Clastres, Pierre

1989 Society Against the State. Essays in Political Anthropology. New York: Zone Books.

Deleuze, Gilles - Guattari, Félix

1987 A Thousand Plateaus. Capitalism and Schizophrenia. London - New York: Continuum International Publishing Group. 
ELYACHAR, Julia

2010 Phatic Labor, Infrastructure, and the Question of Empowerment in Cairo. American Ethnologist 37(3):452-64.

FERGuSON, James

1994 Expectation of Modernity. Myths and Meaning of Urban Life on the Zambian Copperbelt. Berkeley: University of California Press.

FrEEMAN, Derek

1983 Margaret Mead and Samoa. The Making and Unmaking of an Anthropological Myth. Cambridge, Mass.: Harvard University Press.

GRIMSHAw, Anna

2001 The Ethnographer's Eye. Ways of Seeing in Modern Anthropology. Cambridge, UK - New York: Cambridge University Press.

Houseman, Michael - Severi, Carlo

1998 Naven, or the Other Self. A Relational Approach to Ritual Action. Leiden Boston - Köln: Brill.

Humphrey, Caroline

2002 The Unmaking of Soviet Life. Everyday Economies after Socialism. Ithaca, N.Y.: Cornell University Press.

Jensen, Gordon D. - SurYani, Luh Ketut

1992 The Balinese People. A Reinvestigation of Character. Singapore - New York: Oxford University Press.

Kockelman, Paul

2013 Agent, Person, Subject, Self. A Theory of Ontology, Interaction, and Infrastructure. Oxford - New York: Oxford University Press.

LARKIN, Brian

2008 Signal and Noise. Media, Infrastructure, and Urban Culture in Nigeria. Durham - London: Duke University Press. (A John Hope Franklin Center Book.)

LUHMANN, Niklas

1996 Social Systems (Writing Science). Stanford, Calif.: Stanford University Press. MAURER, Bill

2005 Mutual Life, Limited. Islamic Banking, Alternative Currencies, Lateral Reason. New Jersey - Woodstock: Princeton University Press.

MEAD, Margaret

1928 Coming of Age in Samoa. New York: Harper Collins.

MEAD, Margaret - MaCGREGOR, Frances Cook

1951 Growth and Culture. A Photographic Study of Balinese Childhood. New York: Putnam.

NAVARO-YASHIN, Yael

2002 Faces of the State. Secularism and Public Life in Turkey. Princetown, New Jersey: Princeton University Press.

PINK, Sarah

2007 Doing Visual Ethnography. Images, Media and Representation in Research. London - Thousand Oaks, Calif.: Sage. 
SAFONOVA, Tatiana - SÁNTHA, István

2007 Companionship among Evenki of Eastern Buryatia. The Study of Flexible and Stable Elements of Culture. Halle/Saale: Max Planck Institut. (Halle Working Papers of Max Planck Institute for Social Anthropology No 99.)

2013 Culture Contact in Evenki Land. A Cybernetic Anthropology of Baikal Region. Leiden - Boston: Brill - Global Oriental.

SÁNTHA, István

2011 Az evenkik drágaköve. Nefritbányászat a tajgában [The Precious Stone of the Evenki. Nephrite Mining in the Taiga]. Földgömb 13(4):6-27.

ScotT, James

2009 The Art of Not Being Governed. An Anarchist History of Upland Southeast

SERRES, Michel Asia. New Haven, C.T.: Yale University Press.

2007 The Parasite. Minneapolis - London: University of Minnesota Press.

SHIRokogoroff, Semen Mihailovich

1929 Social Organization of the Northern Tungus. London: Garland Publishing Inc. SILVERMAN, David

1993 Interpreting Qualitative Data. Methods for Analysing Talk, Text and Interaction. London - Thousand Oaks, Calif.: Sage.

SNEATH, David

2007 The Headless State. Aristocratic Orders, Kinship Society, and Misrepresentations of Nomadic Inner Asia. New York: Columbia University Press.

SSORIN-CHAIKOV, Nikolai

2003 The Social Life of the State in Subarctic Siberia. Stanford: Stanford University Press.

STENGERs, Isabelle

2013 Introductory Notes on an Ecology of Practices. Cultural Studies Review 11(1):183-96.

Thompson, Niobe

2008 Settlers on the Edge. Identity and Modernization on Russia's Arctic Frontier. Vancouver: UBC Press.

Tsing, Anna

1993 In the Realm of the Diamond Queen. Marginality in an Out-of-the-Way Place. Princetown, N.J.: Princetown University Press.

VoLKov, Vadim

2002 Violent Entrepreneurs. The Use of Force in the Making of Russian Capitalism.

ŽıžEK, Slavoj Ithaca, N.Y.: Cornell University Press.

1989 The Sublime Object of Ideology. London: Verso. 
Tatiana Safonova, candidate of science (2009), Saint Petersburg State University, 20032013 she worked at Centre for Independent Social Research. She published articles on the problems of natural and cultural conservation in post-soviet Russia, anthropology of Siberia, and ethnomethodological studies. She has an MPhil in Social Anthropology at Cambridge University (2014). Recently she works on her PhD project at Central European University (Budapest) on the relationship between human and plants in Hungary. Email-address: tvsafonova@gmail.com

István Sántha, PhD (2004), Eötvös University, Budapest, is a senior research fellow at the Research Centre for the Humanities at the Hungarian Academy of Science. He has published articles on the problems of modern hunter-gatherers in East Siberia and their culture contact strategies with hierarchical societies. Recently he initiated a new project in the frames of Regional History Research Team in collaboration between Research Centre for the Humanities and the Institute of National Remembrance on the topic How the Word War II and the post war period form the life and the strategies of the people in South Vertes Mountain (Hungary). Email-address: santha.istvan@btk.mta.hu 